\title{
Big Data, Scientific Programming, and Its Role in Internet of Industrial Things: A Decision Support System
}

\author{
Ju Li ${ }^{1},{ }^{1}$ Muhammad Nazir Jan, ${ }^{2}$ and Mohammad Faisal ${ }^{3}$ \\ ${ }^{1}$ Chongqing Technology and Business Institute, Chongqing 401520, China \\ ${ }^{2}$ Department of Computer Science, University of Swabi, Swabi, Pakistan \\ ${ }^{3}$ Department of Computer Science and IT, University of Malakand, Chakdara, KP, Pakistan \\ Correspondence should be addressed to Ju Li; liju87031@gmail.com
}

Received 17 August 2020; Revised 11 September 2020; Accepted 15 September 2020; Published 6 October 2020

Academic Editor: Habib Ullah Khan

Copyright (C) $2020 \mathrm{Ju} \mathrm{Li}$ et al. This is an open access article distributed under the Creative Commons Attribution License, which permits unrestricted use, distribution, and reproduction in any medium, provided the original work is properly cited.

\begin{abstract}
Big data is a challenging issue as its volume, shape, and size need to be modified in order to extract important information for a specific purpose. The amount of data is rising with the passage of time. This increase in volume can be a challenging issue to analyze the data for smooth industry and the Internet of things. Several tools, techniques, and mechanisms are available to support the handling and management process of such data. Decision support systems can be one of the important techniques which can support big data in order to make decisions on time. The proposed study presents a decision support system to deal with big data and scientific programming for the Industrial Internet of Things. The study has used the tool of SuperDecisions to plot the hierarchy of situations of big data and scientific programming and to select the best alternative among the available.
\end{abstract}

\section{Introduction}

Big data is termed to be a hot area of research which needs to be shaped in order to derive and extract meaningful information for the specific purpose of research. The data exist in different forms including structured, unstructured, and semistructured. Deriving and extracting meaningful insights from data is quite difficult. Several tools and techniques exist to overcome these deficiencies. Still, researchers try to come with a solution to extract meaningful information from the data of Industrial Internet of Things (IIoTs) in an effective and efficient way.

Decision-making based on multicriteria is one of the most efficient problems solving mean to select appropriate decision among the number of choices. Due to its effectiveness and potential, it is exploited in various domains such as computer science and IT, agriculture, and business sector. The research finds novel means to make the decision support system for the problems of various application domains by using multiple criteria in integration with machine learning and artificial intelligence. Decision support system plays an important role in real life [1-7]. It is one of the major and difficult tasks which ultimately results in success or failure. For example, in the context of a business or organization, the decision support system serves the midand higher-level management and assists people in making decision about certain problems that rapidly change and also not easy to be specified. Decision-making becomes more difficult in situations where it is based on multiple criteria. The current approaches for solving issue of decision support system is capable with power of multicriteria decision support system in order to support the decision makers in taking the right decision in situation of complexity. Researchers try to use multicriteria-based decision support system to integrate the effectiveness of power of machine learning algorithms to provide an intelligent decisionmaking alternative [8-10]. Decision support systems can be exploited in almost any domain to solving decision problems. Various domains exploit the theories and methods used for decision-making based on simple to more advanced $[11,12]$.

The contribution of the proposed study is to offer a decision support system for selecting the most appropriate alternative (vendor) from the available choices. The tool of 
SuperDecisions was considered for experimental process of the proposed research. The goal of the research was based on the defined criteria for selecting the appropriate choice. The results show that the method is effective for decision-making of selecting vendor.

The organization of the paper is as follows: Section 2 represents the related work to the proposed research. Section 3 shows the research methodology with experimental setup and use of tool for decision support system. The paper is concluded in Section 4.

\section{Related Work}

Several studies exist related to the big data and its scientific programming for Industrial Internet of Things. In this examination, the authors proposed a blockchain-dependent data sharing scheme that entirely considers efficiency as well as security of data sharing. In this plan, a hyperledger fabric and identity authentication-dependent secure data sharing structure was designed for the data sharing security. Additionally, a network recognition algorithm was proposed to partition the customers into various data sharing networks as per the comparability of mark data. The exploratory outcomes demonstrate that the proposed conspire is successful for efficient and secure data sharing among various customers [13]. This work presents a procedure data examination stage worked around the idea of industry 4.0 [14]. The platform uses the big data software tools, ML algorithms, and state-of-the-art IIoT platforms. The displaying results indicated that, in situations where process information about the procedure wonders within reach is restricted, information-driven delicate sensors are helpful instruments for predictive data investigation. In this article, a novel model is developed in the perspective of manufacturing progression that reviews the key big data analytics (BDA) capabilities. The findings are beneficial for the companies in order to understand big data potential implications as well as their analytics capabilities for their manufacturing processes and efficient BDA-enabler infrastructure design [15]. In this study, for big data and cognitive Internet of things, a new architecture is proposed. The planned architecture helps the computing systems through combining Data Lake and WareHouse, as well as for the collection of heterogeneous data, a tool is defined [16].

In this article, for industrial data processing, an Industrial Internet of Things cloud-fog hybrid network framework was proposed. The results have shown that the proposed framework reduces effectively the delay processing of industrial data [17]. In this study, a systematic strategy was used to review the weaknesses as well as strengths of opensource technologies for stream processing and big data to set up its usage for industry 4.0 use cases [18]. In this study, functional and structural properties of cloud manufacturing were analyzed, and a business intelligence architecture was proposed that plans to empower distributing pertinent KPIs identified with intrigued process data, with the helpful layer of dependability [19]. This paper examines the current big data analytics technologies, strategies, as well as algorithms that can prompt the improvement of insightful Industrial
TABle 1: Different areas of decision support system.

\begin{tabular}{lc}
\hline Application domain & Reference \\
\hline Business sector & {$[9,21-23]$} \\
Computer field & {$[24-27]$} \\
General problem solving & {$[28-34]$} \\
Industrial domain & {$[35-40]$} \\
Medical field & {$[8,41,42]$} \\
People safety & {$[43,44]$} \\
Supply chain & {$[10,45-47]$} \\
Sustainable computing & {$[48]$} \\
Waste management & {$[49-51]$} \\
Energy sector & {$[52-54]$} \\
Disaster management & {$[55,56]$} \\
Information about DSS & {$[57,58]$} \\
Environmental side & {$[59]$} \\
\hline
\end{tabular}

Internet of Things frameworks. We devise a scientific classification by characterizing and classifying the literature based on essential factors (for example, analytics types, industrial analytics applications, requirements, analytics techniques, analytics tools, and data sources). The case studies and frameworks of the different endeavours were presented that have profited by BDA [20].

\section{Research Method}

With the passage of time, the size and volume of data are increasing. These data will reach a situation where their management and analysis will be a challenging issue. For the analysis and management of big data, there is need of tools and techniques to properly analyze, organize, and extract meaningful information for a specific purpose. The role of decision support system is obvious in different areas of research. Decision support system is a system where the decision can be made based on some criteria to evaluate particular circumstances. The proposed research identified some of the areas where decision support system is helpful in making the decision. Table 1 shows some of the research areas of decision support system.

Figure 1 represents some of the research area domains of the decision support system along with the number of publications.

The current study proposes decision support system in order to select the most appropriate vendor from the available alternatives. The tool of SuperDecisions was used for the experimental process of the proposed study. The goal of the study is to select the most suitable alternative based on some defined criteria. Figure 2 shows the hierarchy followed for plotting the goal, criteria, and alternatives of the proposed study. The attributes of criteria are selected generally which cover most of the criteria of the vendor for the purpose of selection.

The process of giving suitable weights to each criterion against alternatives, and vice versa, was given through experts in the field. Figure 3 shows criteria with their scores for the alternative (Vendor 1). The consistency ratio was checked for Vendor 1 which was calculated as 0.094 . 


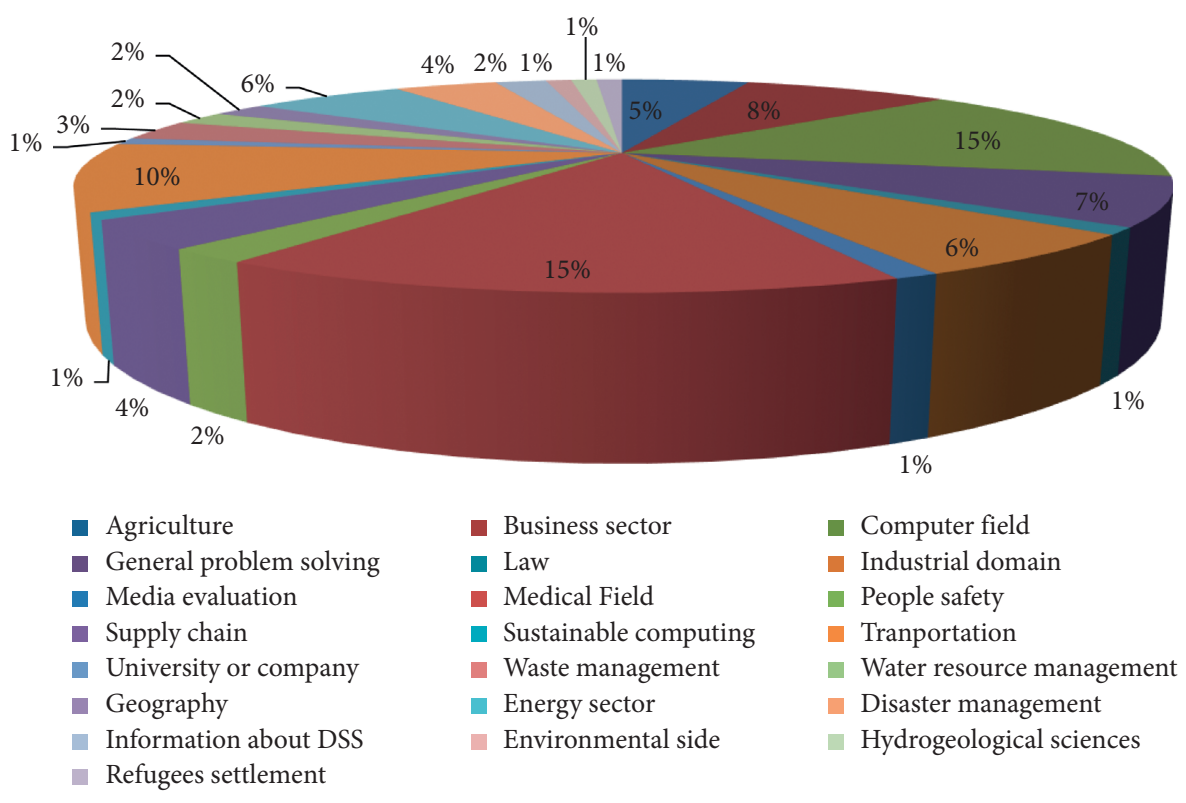

Figure 1: Applications of DSS in different domains along with the number of publications.

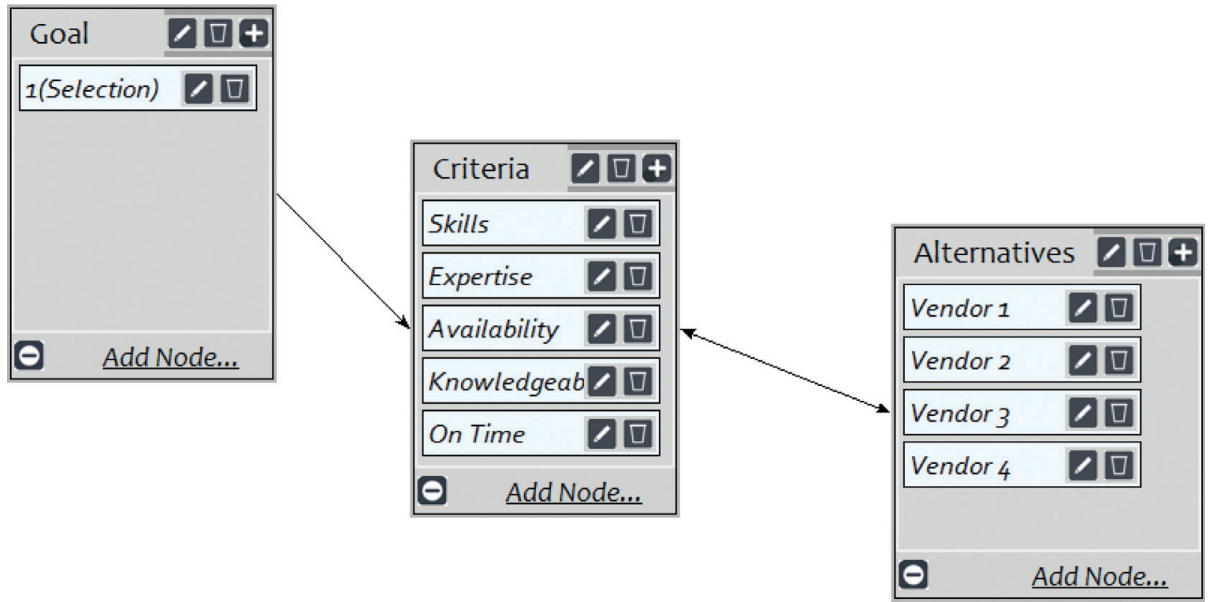

Figure 2: Hierarchy of the proposed study using SuperDecision.

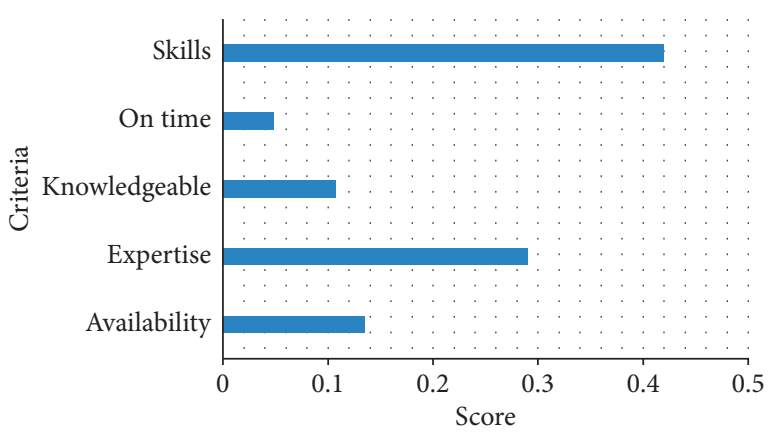

Figure 3: Criteria with their scores for the alternative (Vendor 1).

Figure 4 shows criteria with their scores for the alternative (Vendor 2). The consistency ratio was checked for Vendor 2 which was calculated as 0.043 .
Figure 5 shows criteria with their scores for the alternative (Vendor 3). The consistency ratio was checked for vendor 3 which was calculated as 0.045 .

Figure 6 shows criteria with their scores for the alternative (Vendor 4). The consistency ratio was checked for Vendor 4 which was calculated as 0.082 .

After calculating all the pairwise comparisons for the goal, criteria, and alternatives, a summarized matrix of unweighted and weighted matrix were obtained. These were then converted to limit matrix which is shown in Table 2.

The overall score for the goal, criteria, and alternatives are shown in Figure 7. This figure shows the normalization by cluster and the limitation of the calculations.

Figure 8 shows the final score of the vendors for the ideal, normal, and raw cases. This was obtained from the overall process of calculations. From this, it is concluded that 


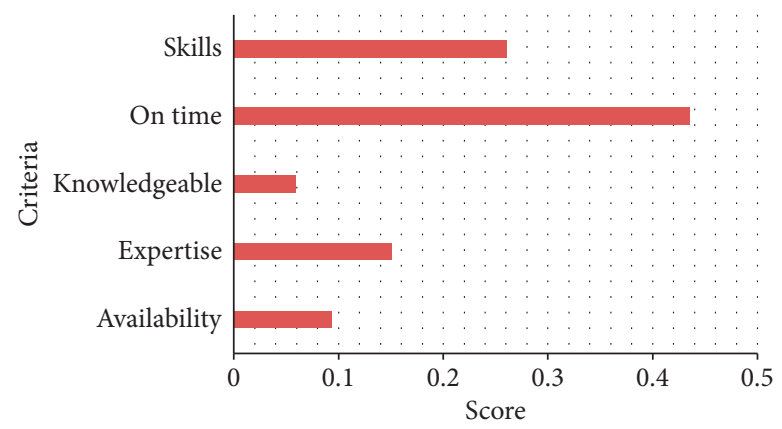

Figure 4: Criteria with their scores for the alternative (Vendor 2).

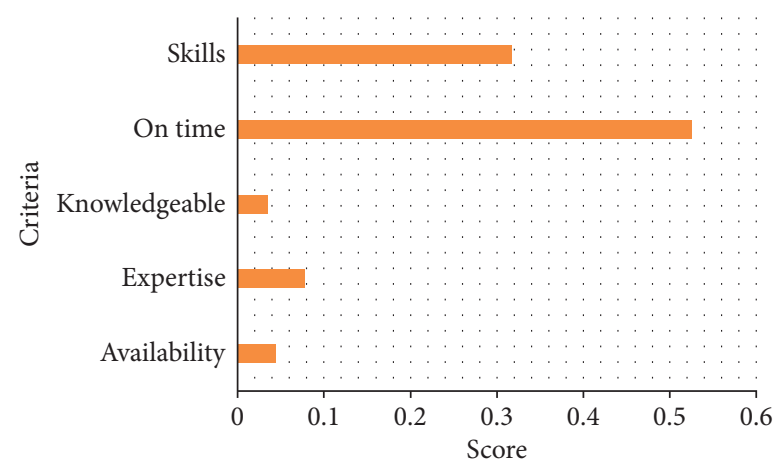

Figure 5: Criteria with their scores for the alternative (Vendor 3).

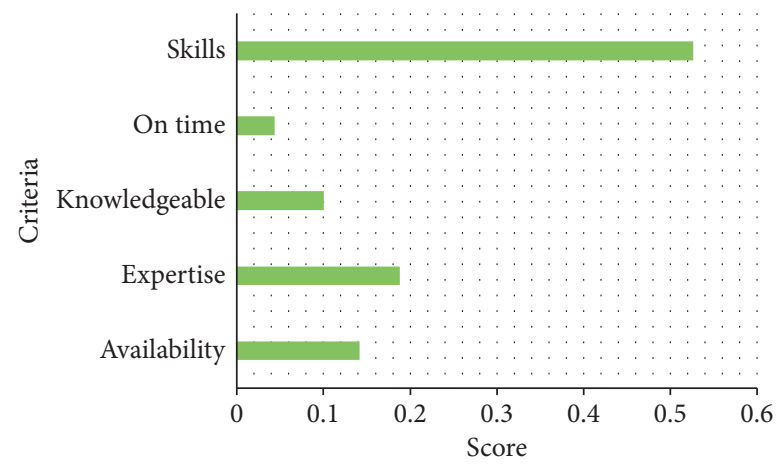

Figure 6: Criteria with their scores for the alternative (Vendor 3).

TABLE 2: Limit matrix.

\begin{tabular}{|c|c|c|c|c|c|c|c|c|c|c|}
\hline & Vendor 1 & Vendor 2 & Vendor 3 & Vendor 4 & Availability & Expertise & Knowledgeable & On time & Skills & Selection \\
\hline Vendor 1 & 0.000 & 0.000 & 0.000 & 0.000 & 0.463 & 0.402 & 0.476 & 0.485 & 0.651 & 0.000 \\
\hline Vendor 2 & 0.000 & 0.000 & 0.000 & 0.000 & 0.275 & 0.325 & 0.254 & 0.276 & 0.167 & 0.000 \\
\hline Vendor 3 & 0.000 & 0.000 & 0.000 & 0.000 & 0.177 & 0.157 & 0.177 & 0.153 & 0.119 & 0.000 \\
\hline Vendor 4 & 0.000 & 0.000 & 0.000 & 0.000 & 0.085 & 0.115 & 0.093 & 0.087 & 0.063 & 0.000 \\
\hline Availability & 0.135 & 0.093 & 0.044 & 0.142 & 0.000 & 0.000 & 0.000 & 0.000 & 0.000 & 0.136 \\
\hline Expertise & 0.290 & 0.151 & 0.078 & 0.188 & 0.000 & 0.000 & 0.000 & 0.000 & 0.000 & 0.302 \\
\hline Knowledgeable & 0.107 & 0.059 & 0.036 & 0.101 & 0.000 & 0.000 & 0.000 & 0.000 & 0.000 & 0.068 \\
\hline On time & 0.048 & 0.436 & 0.526 & 0.044 & 0.000 & 0.000 & 0.000 & 0.000 & 0.000 & 0.035 \\
\hline Skills & 0.420 & 0.261 & 0.317 & 0.526 & 0.000 & 0.000 & 0.000 & 0.000 & 0.000 & 0.459 \\
\hline 1 (selection) & 0.000 & 0.000 & 0.000 & 0.000 & 0.000 & 0.000 & 0.000 & 0.000 & 0.000 & 0.000 \\
\hline
\end{tabular}




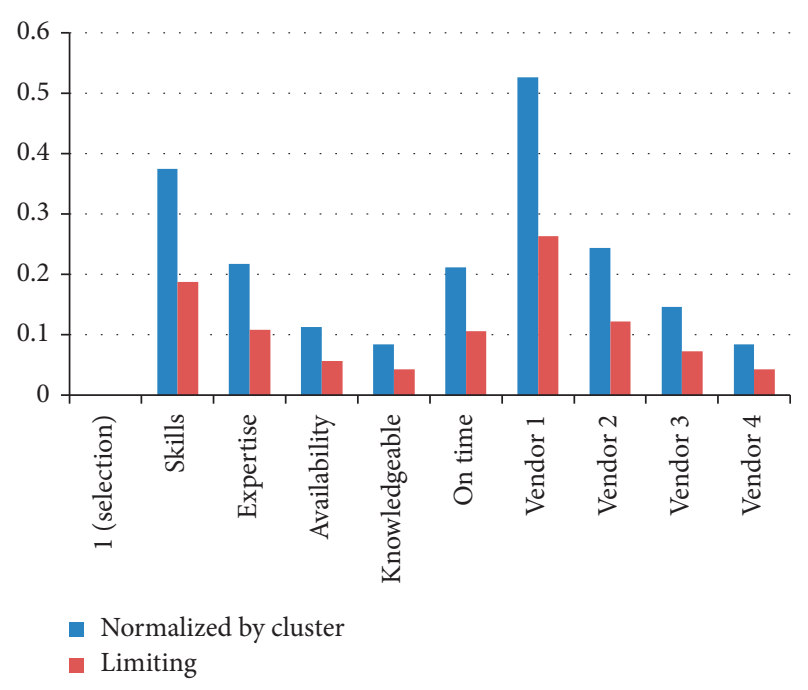

Figure 7: Overall score of goal, criteria, and alternative.

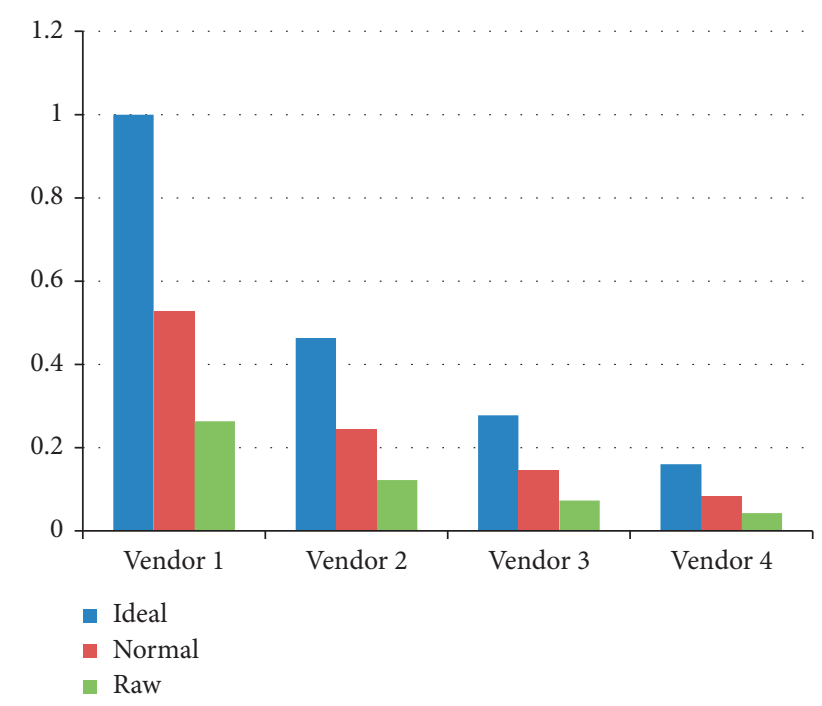

Figure 8: Calculated score of vendors for three cases (ideal, normal, and raw).

Vendor 1 is the best choice among the available alternatives followed by Vendor 2, and so on.

\section{Conclusions}

With the advancements in technology and communication of different devices, the size and volume of data are increasing with the passage of time. For the analysis and management of big data, there is a need of tools and techniques to properly analyze, organize, and extract meaningful information for a specific purpose. Big data is a challenging issue as its volume, shape, and size need to be modified in order to extract important information for a specific purpose. The amount of data is rising with the passage of time. Several tools, techniques, and mechanisms are available to support the handling and management process of such data. Decision support systems can be one of the important techniques which can support big data in order to make decisions on time. The proposed study presents a decision support system to deal with big data and scientific programming for the Industrial Internet of Things by using the tool of SuperDecisions to plot the hierarchy of situations of big data and scientific programming and to select the best alternative among the available. Results of the experiments show that the proposed decision support system is effective in terms of selecting the most appropriate alternative which is vendor in situation of multicriteria.

\section{Data Availability}

No data are available.

\section{Conflicts of Interest}

The authors declare no conflicts of interest.

\section{Acknowledgments}

The authors acknowledge the Chongqing Municipal Education Commission Science and Technology Research Program and Computer System Robot Gas Detection Research Funding Project (KJQN201804006).

\section{References}

[1] T. Ahmad, Y. Ma, M. Yahya, B. Ahmad, S. Nazir, and A. U. Haq, "Object detection through modified YOLO neural network, an intelligent decision support system," Scientific Programming, vol. 2020, Article ID 8403262, 10 pages, 2020.

[2] H.-U. Rahman, H. K. Bamma, S. Nazir, S. Shahzad, and T. Hodosi, "A sourcing decision model for application maintenance services," in Proceedings of the 3rd International Conference on Science in Information Technology (ICSITech), Bandung, Indonesia, October 2017.

[3] A. Khan, J. Li, A. U. Haq et al., "Partial observer decision process model for crane-robot action," Scientific Programming, vol. 2020, Article ID 6349342, 14 pages, 2020.

[4] S. Nazir, S. Ali, M. Yang, and Q. Xu, "Deep learning algorithms and multi-criteria decision making used in big data-a systematic literature review," Security and Communication Networks, vol. 2020, Article ID 2836064, 18 pages, 2020.

[5] S. Nazir, S. Shahzad, S. Mahfooz, and M. N. Jan, "Fuzzy logic based decision support system for component security evaluation," International Arab Journal of Information and Technology, vol. 15, pp. 1-9, 2018.

[6] S. Nazir, S. Shahzad, A. Ullah, and A. Hussain, "Identification and analysis of project attributes affecting the decision of requirement elicitation technique," in Proceedings of the 2017 National Graduate Conference, Islamabad, Pakistan, April 2017.

[7] J. Zhang, S. Nazir, A. Huang, and A. Alharbi, "Multicriteria decision and machine learning algorithms for component security evaluation: library-based overview," Security and Communication Networks, vol. 2020, Article ID 8886877, 14 pages, 2020.

[8] S. Safdar, S. Zafar, N. Zafar, and N. F. Khan, "Machine learning based decision support systems (DSS) for heart disease diagnosis: a review," Artificial Intelligence Review, vol. 50, no. 4, pp. 597-623, 2018. 
[9] I. Aouadni and A. Rebai, "Decision support system based on genetic algorithm and multi-criteria satisfaction analysis (MUSA) method for measuring job satisfaction," Annals of Operations Research, vol. 256, pp. 3-20, 2017.

[10] M. Jemmali, M. Alharbi, and L. K. B. Melhim, "Intelligent decision-making algorithm for supplier evaluation based on multi-criteria preferences," in Proceedings of the 2018 1st International Conference on Computer Applications \& Information Security (ICCAIS), pp. 1-5, Riyadh, Saudi Arabia, April 2018.

[11] L. S. R. Supriadi and L. Sui Pheng, "Knowledge based decision support system (KBDSS)," in Business Continuity Management in Construction Singapore, pp. 155-174, Springer, Singapore, 2018.

[12] A. Alaeddini and K. G. Murty, "DSS (decision support system) for allocating appointment times to calling patients at a medical facility,"“DSS (decision support system) for allocating appointment times to calling patients at a medical facility," in Case Studies in Operations Research: Applications of Optimal Decision Making, K. G. Murty, Ed., pp. 83-109, Springer, New York, NY, USA, 2015.

[13] J. Chi, Y. Li, J. Huang et al., "A secure and efficient data sharing scheme based on blockchain in industrial internet of things," Journal of Network and Computer Applications, vol. 167, Article ID 102710, 2020.

[14] J. C. Kabugo, S.-L. Jämsä-Jounela, R. Schiemann, and C. Binder, "Industry 4.0 based process data analytics platform: a waste-to-energy plant case study," International Journal of Electrical Power \& Energy Systems, vol. 115, Article ID 105508, 2020.

[15] A. Belhadi, K. Zkik, A. Cherrafi, S. R. M. Yusof, and S. El Fezazi, "Understanding big data analytics for manufacturing processes: insights from literature review and multiple case studies," Computers \& Industrial Engineering, vol. 137, Article ID 106099, 2019.

[16] M. S. Hadj Sassi, F. G. Jedidi, and L. C. Fourati, "A new architecture for cognitive internet of things and big data," Procedia Computer Science, vol. 159, pp. 534-543, 2019.

[17] W. Liu, G. Huang, A. Zheng, and J. Liu, "Research on the optimization of IIoT data processing latency," Computer Communications, vol. 151, pp. 290-298, 2020.

[18] R. Sahal, J. G. Breslin, and M. I. Ali, "Big data and stream processing platforms for industry 4.0 requirements mapping for a predictive maintenance use case," Journal of Manufacturing Systems, vol. 54, pp. 138-151, 2020.

[19] J. Ordieres-Meré, J. Villalba-Díez, and X. Zheng, "Challenges and opportunities for publishing IIoT data in manufacturing as a service business," Procedia Manufacturing, vol. 39, pp. 185-193, 2019.

[20] M. H. Ur Rehman, I. Yaqoob, K. Salah, M. Imran, P. P. Jayaraman, and C. Perera, "The role of big data analytics in industrial internet of things," Future Generation Computer Systems, vol. 99, pp. 247-259, 2019.

[21] X. Fu, X.-J. Zeng, X. Luo, D. Wang, D. Xu, and Q.-L. Fan, "Designing an intelligent decision support system for effective negotiation pricing: a systematic and learning approach," Decision Support Systems, vol. 96, pp. 49-66, 2017.

[22] J. Korczak, H. Dudycz, B. Nita, P. Oleksyk, and A. Kaźmierczak, "Extension of intelligence of decision support systems: manager perspective," in Information Technology for Management: New Ideas and Real Solutions, pp. 35-48, Springer, Cham, Switzerland, 2017.

[23] G. Silahtaroğlu, "Implementing adaptive strategies of decision support systems during crises," Implementing adaptive strategies of decision support systems during crises," in Global Business Strategies in Crisis: Strategic Thinking and Development, Ü. Hacioğlu, H. Dinçer, and N. Alayoğlu, Eds., Springer International Publishing, Cham, Switzerland, pp. 287-302, 2017.

[24] A. Kaklauskas, "Intelligent decision support systems," in Biometric and Intelligent Decision Making Support, pp. 31-85, Springer International Publishing, Cham, Switzerland, 2015.

[25] A. Kaklauskas and R. Gudauskas, "Intelligent decision-support systems and the internet of things for the smart built environment," in Start-Up Creation, pp. 413-449, Woodhead Publishing, Cambridge, UK, 2016.

[26] J. C. Leyva López, P. A. Álvarez Carrillo, D. A. Gastélum Chavira, and J. J. Solano Noriega, "A web-based group decision support system for multicriteria ranking problems," Operational Research, vol. 17, no. 2, pp. 499-534, 2017.

[27] A. Martin, P. Zarate, and G. Camillieri, "A multi-criteria recommender system based on users' profile management,"“A multi-criteria recommender system based on users' profile management," in Multiple Criteria Decision Making: Applications in Management and Engineering, C. Zopounidis and M. Doumpos, Eds., Springer International Publishing, Cham, Switzerland, pp. 83-98, 2017.

[28] T. Bakshi, A. Sinharay, B. Sarkar, and S. K. Sanyal, "A new DST-belief theoretic project selection model for multi-criteria decision support system," Journal of the Institution of Engineers (India): Series C, vol. 96, no. 4, pp. 337-349, 2015.

[29] O. E. Bukharov and D. P. Bogolyubov, "Development of a decision support system based on neural networks and a genetic algorithm," Expert Systems with Applications, vol. 42, no. 15-16, pp. 6177-6183, 2015.

[30] M. Kalinina, "Multi criteria decision support system: preference information and robustness," in New Contributions in Information Systems and Technologies, pp. 641-651, Springer International Publishing, Cham, Switzerland, 2015.

[31] C.-S. Wang, H.-L. Yang, and S.-L. Lin, "To make good decision: a group DSS for multiple criteria alternative rank and selection," Mathematical Problems in Engineering, vol. 2015, Article ID 186970, 15 pages, 2015.

[32] V. Ferretti and G. Montibeller, "Key challenges and metachoices in designing and applying multi-criteria spatial decision support systems," Decision Support Systems, vol. 84, pp. 41-52, 2016.

[33] A. Deaconescu, "Decision support system based on robust design methods," in Proceedings of the 2017 4th International Conference on Biomedical and Bioinformatics Engineering-ICBBE 2017, November 2017.

[34] S. Bouzayane and I. Saad, "Intelligent multicriteria decision support system for a periodic prediction," in Decision Support Systems IX: Main Developments and Future Trends, pp. 97110, Springer International Publishing, Cham, Switzerland, 2019.

[35] I. Karlsson, A. H. C. Ng, A. Syberfeldt, and S. Bandaru, "An interactive decision support system using simulation-based optimization and data mining," in Proceedings of the 2015 Winter Simulation Conference (WSC), December 2015.

[36] R. Sadeghian and M. R. Sadeghian, "A decision support system based on artificial neural network and fuzzy analytic network process for selection of machine tools in a flexible manufacturing system," The International Journal of Advanced Manufacturing Technology, vol. 82, no. 9-12, pp. 1795-1803, 2016.

[37] M. Gomes, F. Silva, F. Ferraz, A. Silva, C. Analide, and P. Novais, "Developing an ambient intelligent-based decision 
support system for production and control planning," in Advances in Intelligent Systems and Computing, pp. 984-994, Springer International Publishing, Cham, Switzerland, 2017.

[38] S.-J. Shin, D. B. Kim, G. Shao, A. Brodsky, and D. Lechevalier, "Developing a decision support system for improving sustainability performance of manufacturing processes," Journal of Intelligent Manufacturing, vol. 28, no. 6, pp. 1421-1440, 2017.

[39] J. Gąbka and G. Filcek, "Multiple criteria decision support system for making the best manufacturing technologies choice and assigning contractors," in Advances in Intelligent Systems and Computing, pp. 314-323, Springer International Publishing, Cham, Switzerland, 2018.

[40] M. M. Mabkhot, A. M. Al-Samhan, and L. Hidri, "An ontology-enabled case-based reasoning decision support system for manufacturing process selection," Advances in Materials Science and Engineering, vol. 2019, Article ID 2505183, 18 pages, 2019.

[41] Y. Jiang, B. Qiu, C. Xu, and C. Li, "The research of clinical decision support system based on three-layer knowledge base model," Journal of Healthcare Engineering, vol. 2017, Article ID 6535286, 8 pages, 2017.

[42] Y.-F. Chen, C.-S. Lin, K.-A. Wang et al., "Design of a clinical decision support system for fracture prediction using imbalanced dataset," Journal of Healthcare Engineering, vol. 2018, Article ID 9621640, 13 pages, 2018.

[43] M. Camacho-Collados and F. Liberatore, "A decision support system for predictive police patrolling," Decision Support Systems, vol. 75, pp. 25-37, 2015.

[44] M. Marzouk and B. Mohamed, "Integrated agent-based simulation and multi-criteria decision making approach for buildings evacuation evaluation," Safety Science, vol. 112, pp. $57-65,2019$.

[45] J. Lee, H. Cho, and Y. S. Kim, "Agile supply chain decision support system,"“Agile supply chain decision support system," in Reshaping Society through Analytics, Collaboration, and Decision Support: Role of Business Intelligence and Social Media, L. S. Iyer and D. J. Power, Eds., Springer International Publishing, Cham, Switzerland, pp. 29-50, 2015.

[46] G. Dellino, T. Laudadio, R. Mari, N. Mastronardi, and C. Meloni, "A reliable decision support system for fresh food supply chain management," International Journal of Production Research, vol. 56, no. 4, pp. 1458-1485, 2018.

[47] J. Mar-Ortiz, M. D. Gracia, and N. Castillo-García, "Challenges in the design of decision support systems for port and maritime supply chains," in Exploring Intelligent Decision Support Systems: Current State and New Trends, pp. 49-71, Springer International Publishing, Cham, Switzerland, 2018.

[48] A. K. Sangaiah, A. Abraham, P. Siarry, and M. Sheng, "Intelligent decision support systems for sustainable computing," in Intelligent Decision Support Systems for Sustainable Computing: Paradigms and Applications, pp. 1-6, Springer International Publishing, Cham, Switzerland, 2017.

[49] A. Schwenk-Ferrero and A. Andrianov, "Nuclear waste management decision-making support with MCDA," Science and Technology of Nuclear Installations, vol. 2017, Article ID 9029406, 20 pages, 2017.

[50] S. Kapilan and K. Elangovan, "Potential landfill site selection for solid waste disposal using GIS and multi-criteria decision analysis (MCDA)," Journal of Central South University, vol. 25 , no. 3 , pp. $570-585,2018$.

[51] O. Rybnytska, F. Burstein, A. V. Rybin, and A. Zaslavsky, "Decision support for optimizing waste management," Journal of Decision Systems, vol. 27, no. sup1, pp. 68-78, 2018.
[52] R. Mukhamediev, R. Mustakayev, K. Yakunin, S. Kiseleva, and V. Gopejenko, "Multi-criteria decision support system for RES evaluation," in Proceedings of the 2018 IEEE 12th International Conference on Application of Information and Communication Technologies (AICT), pp. 1-6, Almaty, Kazakhstan, October 2018.

[53] R. I. Mukhamediev, R. Mustakayev, K. Yakunin, S. Kiseleva, and V. Gopejenko, "Multi-criteria spatial decision making supportsystem for renewable energy development in Kazakhstan,” IEEE Access, vol. 7, pp. 122275-122288, 2019.

[54] S. Torabi Moghadam and P. Lombardi, "An interactive multicriteria spatial decision support system for energy retrofitting of building stocks using CommuntiyVIZ to support urban energy planning," Building and Environment, vol. 163, Article ID 106233, 2019.

[55] M. Esmaelian, M. Tavana, F. J. Santos Arteaga, and S. Mohammadi, "A multicriteria spatial decision support system for solving emergency service station location problems," International Journal of Geographical Information Science, vol. 29, no. 7, pp. 1187-1213, 2015.

[56] M. S. E. Mohamed and A. A. Binsultan, "Developing an intelligent decision support system approach for crisis preparedness," in Advances in Intelligent Systems and Computingpp. 690-699, Cham, Switzerland, 2017.

[57] G. Zhang, J. Lu, and Y. Gao, "Decision making and decision support systems," in Multi-Level Decision Making: Models, Methods and Applications, pp. 3-24, Springer, Berlin, Germany, 2015.

[58] A. D. Haidar, "Techniques for intelligent decision support systems," in Construction Program Management-Decision Making and Optimization Techniques, pp. 159-183, Springer International Publishing, Cham, Switzerland, 2016.

[59] P. Hirsch, M. Grochowski, and K. Duzinkiewicz, "Decision support system for design of long distance heat transportation system," Energy and Buildings, vol. 173, pp. 378-388, 2018. 